\title{
Optimization Strategy for Line Loss Reduction of Distribution Network Based on Multi-distributed Photovoltaic Access
}

\author{
Fan Yang ${ }^{1}$, Jun Liu ${ }^{1}$, Bingbing Lu ${ }^{1}$, Luhao Zuo 2,*, Weihua Zhang ${ }^{3}$ \\ ${ }^{1}$ State Grid Shanghai Electric Power Research Institute, 171 Handan Road, Shanghai, China \\ ${ }^{2}$ State Grid Shanghai Jinshan Power Supply Company, 2522 J inshan A venue, Shanghai, China \\ ${ }^{3}$ Shanghai Bijian Intelligent Technology Co., Ltd., Y angpu District, Shanghai, China
}

\begin{abstract}
The number of distributed photovoltaic power generation systems connected to the system is increasing, especially for residents and non-residents. A large amount of photovoltaic grid-connected power brings new problems to the line loss management of the distribution network. This paper proposes a theoretical calculation model of line loss for distribution netw ork with multi-distributed photovoltaic access. This paper adopts the actual case of Shanghai Power Grid, calculates based on the mathematical model proposed, and puts forward targeted optimization suggestions by comparing the simulation analysis results.
\end{abstract}

\section{Introduction}

Distributed photovoltaics (PV) have been introduced into the distribution network more and more widely due to their high flexibility and low pollution. On the one hand, it has changed the network structure and operation mode of the distribution system, and on the other hand, it has also greatly affected the calculation process of the distribution network line loss. With the increasing number of distributed photovoltaic power generation systems connected to the system, especially for residents and non-residents. In the distribution network line loss management, the traditional distribution network line loss calculation formula will have unreasonable line loss when calculating the line loss of the station area with distributed photovoltaic power generation users. For example, the line loss result is obviously small, or even the result is negative[1]. At the same time, a large amount of PV grid power brings new problems to the line loss management of the station area. Therefore, studying the impact of multi-distributed photovoltaic access on the line loss of the distribution network and the study of loss reduction strategies are of great significance to improve the development level of distributed PV, improve the level of line loss management of the distribution network, and promote social and economic development.

Therefore, on the basis of the conventional theoretical calculation method of the distribution network, this paper constructs a distribution network line loss calculation model based on equivalent resistance and regression analysis, and then selects a typical distribution network line containing distributed PV in the Shanghai area for physical Model, and finally select the optimal loss reduction measures suitable for the region by comparing the simulation results.

\section{Loss reduction measures for distribution network}

The lines and equipments of each link of power transmission and distribution will produce certain losses. From the perspective of loss composition, the line loss power can be divided into three parts, including fixed loss, variable loss, and other losses. Fixed loss does not change with load changes, generally mainly transformer iron loss, etc.; variable loss changes with load change, mainly refers to transformer copper loss, line resistance loss, etc.; other losses refer to various other caused by reasons such as poor management Power loss, such as metering errors, illegal electricity theft, missed copy and wrong copy, etc[2].

According to the relationship of the power loss in the distribution network components (line or transformer):

$$
\triangle P=3 I^{2} R
$$

In the formula (1): $I$ is the current through each element; $R$ is the resistance of the element. It can be seen that there are two ways to reduce the line loss of the power network: reduce the current flowing through the component and reduce the resistance of the component. Therefore, to reduce the technical loss of the distribution network, the following measures can be taken: (1) Optimizing the network structure; (2) Reasonably selecting the conductor cross section; (3) Balancing the three-phase load of the distribution network; (4) Adjusting the load and reducing the load. Peak filling and valley filling work; (5) Economic operation of transformers; (6) Reactive power compensation of distribution network; For the distribution network of a certain area, the loss reduction potential of different topologies and operation modes are different. In order to optimize the loss reduction measures with great potential

${ }^{*}$ Corresponding author: luhao_zuo@ 163.com 
for loss reduction, it is necessary to calculate the theoretical line loss rate of the overall distribution network before and after the implementation of different loss reduction measures.

\section{Calculation model of distribution network line loss}

\subsection{Distributed photovoltaic model}

Photovoltaic is a typical form of distributed power supply. It can be used as an independent power generation system to supply power to users, or it can be directly connected to the grid after DC power is converted into AC power through an inverter. The power output model of the photovoltaic power station is

$$
P_{\mathrm{PV}}=Y_{\mathrm{PV}} f_{\mathrm{PV}}\left(\frac{R_{\mathrm{T}}}{R_{\mathrm{STC}}}\right)\left[1+\alpha_{\mathrm{P}}\left(T_{\mathrm{P}}-T_{\mathrm{STC}}\right)\right]
$$

In the formula (2), $P_{\mathrm{PV}}$ and $Y_{\mathrm{PV}}$ are the real-time output power and rated power of large-scale photovoltaic power plants; $f_{\mathrm{pV}}$ is the loss factor of photovoltaic cells, which is taken as $0.87 ; R_{\mathrm{T}}$ is the actual solar radiation intensity; $R_{\mathrm{STC}}$ is the solar radiation intensity under standard test conditions, which is $1000 \mathrm{~W} / \mathrm{m} 2 ; \alpha_{\mathrm{p}}$ is the power temperature coefficient of the solar cell module, taking $-0.35 \% /{ }^{\circ} \mathrm{C} ; T_{\mathrm{p}}$ is the actual temperature of the solar cell module; $T_{\mathrm{STC}}$ is the battery temperature under standard test conditions, taking $25^{\circ} \mathrm{C}$.

The main mode of distributed photovoltaic access to the distribution network is shown in Figure 1:

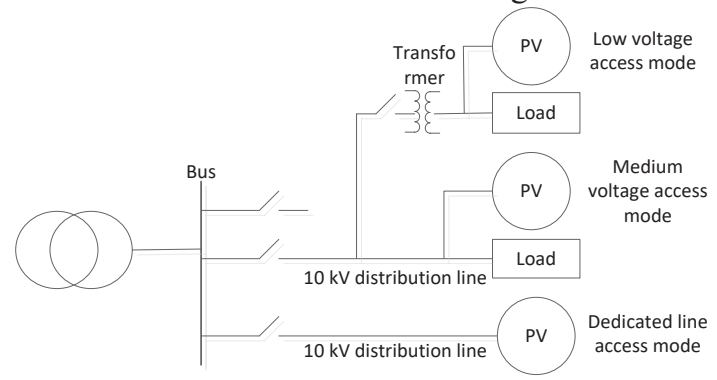

Fig. 1. The main mode of distributed photovoltaic access to the distribution network

\section{$3.210 \mathrm{kV}$ line model}

The $10 \mathrm{kV}$ distribution network transmits electric energy through distribution lines. The distribution lines are divided into two types according to the structure: overhead lines and power cables. In the theoretical calculation of line loss, the resistance value of a certain section of wire at a certain temperature can be calculated according to the following formula[3]:

$$
R_{l}=\rho \frac{L}{S}[1+\alpha(t-20)]
$$

In the formula (3), $R_{l}$ is the corrected value of line resistance at a certain temperature; $\rho$ is the resistivity of the wire material, which is related to the wire type; $L$ is the length of the wire; $S$ is the cross-sectional area of the wire. $\alpha$ represents the resistance temperature correction coefficient $\left[\alpha_{C u}=0.00382\left(1 /{ }^{\circ} \mathrm{C}\right), \alpha_{A l}=\right.$ $\left.0.0036\left(1 /{ }^{\circ} \mathrm{C}\right)\right], t$ represents the ambient temperature, this formula can be applied to the accuracy of the line resistance under different ambient temperatures Calculation.

When the three-phase wires of the line are laid in parallel, the calculation formula of the wire reactance is as follows:

$$
X_{l}=L \times \omega \times\left(4.6 \times \lg \frac{d}{r}+0.5 \times \mu\right) \times 10^{-4}
$$

In the formula (4), $X_{l}$ is the reactance of a singlephase wire; $L$ is the length of the wire; $\omega$ is the angular frequency of the alternating current flowing through the wire; $d$ represents the geometrical average distance between the centers of gravity between the wires, $r$ represents the radius of the wire; $\mu$ represents the relative permeability of the wire, where The relative permeability of non-ferrous metals is 1 .

\subsection{Distribution transformer model}

Transformer loss in $10 \mathrm{kV}$ distribution network mainly includes iron loss and copper loss. Among them, iron loss includes two parts: basic loss and additional loss. Copper loss mainly includes basic copper loss and additional copper loss. Among them, additional copper loss usually refers to additional copper loss, which is caused by skin effect and proximity effect. The copper loss value is small and negligible.

In the actual application of power grid equipment, dual-winding transformers are the most widely used and popular. At present, most transformers in $10 \mathrm{kV}$ power grids are dual-winding transformers. Therefore, when calculating the $10 \mathrm{kV}$ power grid line loss, the transformer components can be equivalent to obtain the equivalent circuit of the dual-winding transformer. RT stands for resistance, Xt stands for reactance, GT stands for conductance, and BT stands for sodium, which are the four main parameters of the transformer. The calculation formula of each parameter is as follows[4]:

$$
\begin{aligned}
R_{T} & =\frac{\Delta P_{k} U_{N}^{2}}{1000 S_{N}^{2}} \\
X_{T} & =\frac{U_{k} \% \times U_{N}^{2}}{100 S_{N}} \\
G_{T} & =\frac{\Delta P_{0}}{1000 U_{N}^{2}} \\
B_{T} & =\frac{I_{0} \% \times S_{N}}{100 U_{N}^{2}}
\end{aligned}
$$

Among (5-8): $\Delta P_{k}$ represents the short-circuit loss of the transformer, $\Delta P_{0}$ represents the no-load loss of the transformer, $U_{k} \%$ represents the percentage of shortcircuit voltage, and $I_{0} \%$ represents the percentage of noload current.

\subsection{Regression analysis method}


The main influencing factors of transformer loss are transformer model, capacity and transformer load factor. However, the transformer models and capacities in the distribution network are complex and diverse, and the load rates of the transformers are also different. It is obviously unrealistic to calculate the power loss of each transformer one by one. To solve the above problems, regression analysis method in probability statistics is introduced. The regression analysis method uses the principle of statistical analysis, selects the appropriate independent variable factors, and calculates the loss of the transformer by establishing a mathematical model and listing the regression equation. The specific method is as follows[2]:

(1) Select the no-load loss and short-circuit loss of the same model and different capacity distribution transformers as the regression analysis samples; (2) Perform regression analysis on the selected samples of different types of distribution transformers; (3) Establish different models The regression equation of the no-load loss and short-circuit loss of the electric transformer; (4) Count the average capacity of the same type distribution transformer in the distribution network, and bring it into the regression equation to obtain the average no-load loss and short-circuit loss of this type of transformer; (5) The algebraic sum of the losses of different types of distribution transformers can obtain the losses of all the distribution transformers in the distribution network.

\section{Forward push-back algorithm with distributed photovoltaic}

As the scale of the distribution network increases, the complexity of power flow calculation increases linearly. The forward-backward power flow algorithm is suitable for solving the power flow of large-scale radial distribution systems. It is one of the commonly used power flow algorithms for distribution networks. When performing power flow calculation in a distribution network with distributed PV, PV are treated as PI type nodes. The algorithm flow chart of the forwardbackward method with distributed photovoltaic is shown in Figure 2.

1) Read the original data of the distribution network to determine the location and node type of distributed PV. Form a nodal impedance matrix and set the maximum number of iterations.

2) Initialize system parameters and initial values of distributed photovoltaic. Determine the P and Q values corresponding to the loads of all nodes; calculate the initial reactive power $\mathrm{Q}_{0}$ according to the $\mathrm{P}$ and $\mathrm{I}$ values corresponding to the PI-type distributed photovoltaic.

3) Forward calculation of the power distribution of the distribution network: starting from the end node of the radial network, calculating the power loss, current value, and head end power of each branch on the basis of the initial voltage and power, and so on, until the root node .

4) Back-generation calculation of the voltage distribution of the active distribution network: Knowing the voltage and power of the root node at the head end, calculate the voltage value of each node, and so on, until the end of the line.

5) Update the reactive power of PI-type distributed PV.

6) Determine whether the reactive power exceeds the limit: According to the updated reactive power of the PI node, determine whether the reactive power exceeds the limit. If there is a limit violation, the PI type node is converted to a PQ node, and the node injection current is corrected.

7) Check whether the convergence: Determine whether the voltage amplitudes of all PV nodes and nonPV nodes meet the requirements. If the above two points are met at the same time, the iteration will converge, and execute 8); otherwise, determine whether the maximum number of iterations is reached, and if it is met, then execute 8); if it is not established, execute 3 ).

8) Output the power flow calculation result and the program ends.

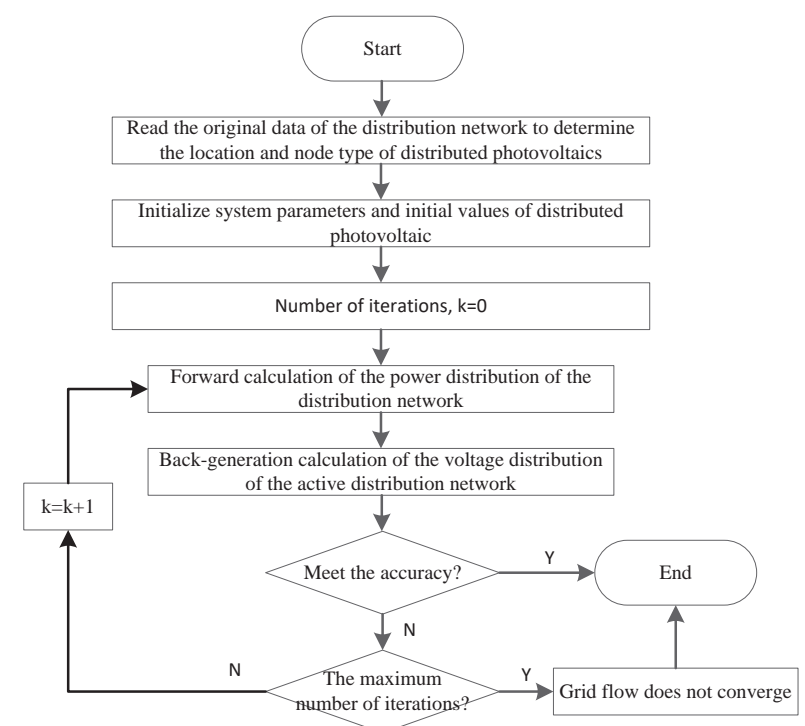

Fig. 2. The algorithm flow chart of the forward-backward method with distributed photovoltaic

\section{Case calculation analysis}

Taking the Shanghai distribution network as a case, select a typical $10 \mathrm{KV}$ warehouse line: Ji 20 West Yangtze River Station B/ Ji 50 Yijingyuan South Station B feeder, select the operating data on July 24, 2020, and change the line Different loss reduction measures are analyzed for loss reduction potential. The line has 19 public transformers, 3 special transformers, and 1 distributed photovoltaic power station, including 2 SCB10 transformers, 17 S11 transformers, 3 SBH11 transformers, 15 transformers with a capacity of 500KVA, and 3 transformers with a capacity One transformer for $800 \mathrm{KVA}, 1000 \mathrm{KVA}, 1250 \mathrm{KVA}$, $1500 \mathrm{KVA}, 1600 \mathrm{KVA}$. The total length of the line is 6992.56 meters, and the line models include DL_YJV0270, DL_YJV02-95, DL_YJV02-120, DL_YJV02-240, DL_YJV02-400, etc. The circuit topology is shown in Figure 3, and the real-time current value is shown in Figure 4. 
According to the line loss calculation model proposed in this paper, combined with the operating parameters and equipment parameters of the distribution network line, the current theoretical line loss rate of the $10 \mathrm{kV}$ grid layer is $2.45 \%$, which is $0.05 \%$ lower than the actual statistical value. After implementing different loss reduction measures, the calculation results of the theoretical line loss rate of the $10 \mathrm{kV}$ line are shown in Table 1.

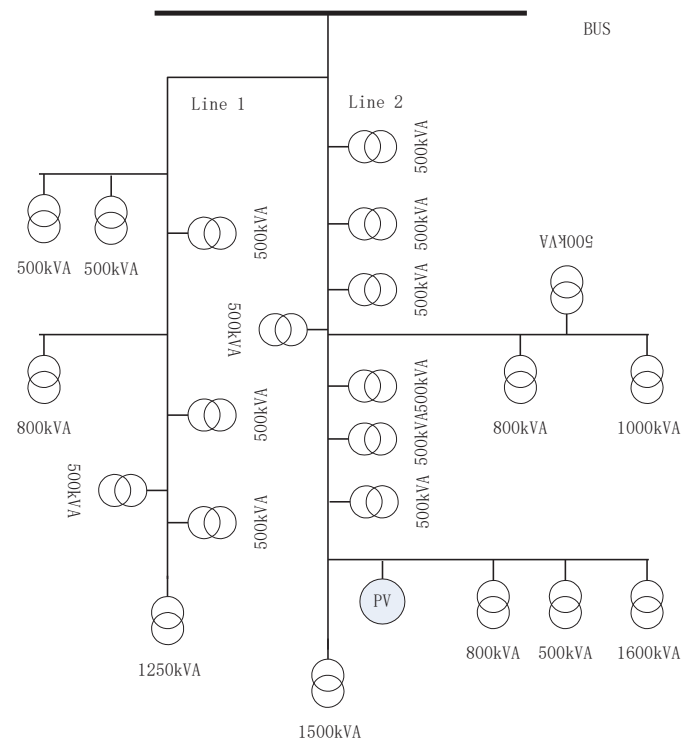

Fig. 3. The circuit topology of Ji 20 West Yangtze River Station B/ Ji 50 Yijingyuan South Station B feeder

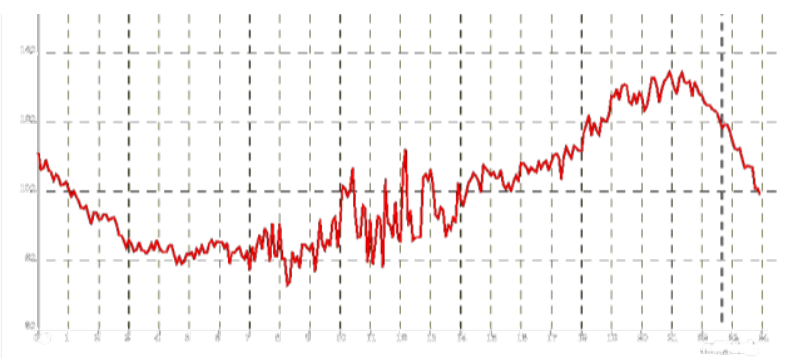

Fig. 4. The real-time current value of Ji 20 West Yangtze River Station B/ Ji 50 Yijingyuan South Station B feeder

Table 1. Implementation effects of different loss reduction measures

\begin{tabular}{|c|c|c|c|}
\hline Measures & $\begin{array}{c}\text { Detailed } \\
\text { description }\end{array}$ & $\begin{array}{c}\text { Theoretical } \\
\text { line loss rate } \\
(\%)\end{array}$ & $\begin{array}{c}\text { Line loss } \\
\text { change } \\
\text { rate (\%) }\end{array}$ \\
\hline $\begin{array}{c}\text { Replace the } \\
\text { large cross- } \\
\text { section } \\
\text { conductor }\end{array}$ & $\begin{array}{c}70 / 95 / 120 \mathrm{~mm}^{2} \\
\text { to } 240 \mathrm{~mm}^{2}\end{array}$ & 2.02 & 17.55 \\
\hline $\begin{array}{c}\text { Replacement } \\
\text { of energy- } \\
\text { saving } \\
\text { distribution } \\
\text { transformer }\end{array}$ & $\begin{array}{c}\text { SCB10 type } \\
\text { distribution } \\
\text { transformer } \\
\text { replaced with } \\
\text { S11 type } \\
\text { distribution } \\
\text { transformer }\end{array}$ & 2.40 & 2.04 \\
\hline $\begin{array}{c}\text { Increase } \\
\text { reactive power } \\
\text { compensation }\end{array}$ & $\begin{array}{c}\text { Increase the } \\
\text { power factor to } \\
0.96\end{array}$ & 2.14 & 12.65 \\
\hline Change of PV & Move to the & 2.50 & -2.04 \\
\hline
\end{tabular}

\begin{tabular}{|c|c|c|c|}
\hline \multirow{3}{*}{$\begin{array}{c}\text { connection } \\
\text { position }\end{array}$} & front & & \\
\cline { 2 - 4 } & $\begin{array}{c}\text { Move to mid- } \\
\text { range }\end{array}$ & 2.30 & 6.12 \\
\cline { 2 - 4 } & No access & 2.55 & -4.08 \\
\hline
\end{tabular}

From the above calculation results, it can be seen that for the $10 \mathrm{kV}$ distribution network line, the replacement of small cross-section conductors has the greatest loss reduction potential, followed by the addition of reactive power compensation, the replacement of energy-saving distribution transformers, and the integration of distributed PV into the load center. At the same time, it can be seen through theoretical calculations that the correct access of distributed PV has a positive effect on improving the line loss rate of the distribution network. The equipment level, structure, and operation mode of the distribution network in different regions are different, so the loss reduction potentials of different loss reduction measures are also different. At the same time, strengthening the investigation and handling of users' breach of contract electricity (excess capacity) and electricity theft through marketing audits is also the main way to reduce management line losses.

\section{Conclusion}

On the basis of traditional line loss calculation methods, a comprehensive use of equivalent resistance method and regression analysis method is used to construct a distribution network line loss calculation model. Using this model can not only calculate the theoretical line loss rate of a single $10 \mathrm{kV}$ line or consolidation line with distributed PV, but also calculate the theoretical line loss rate of the overall distribution network with multidistributed PV in a certain area. In addition, this model and algorithm can calculate the reduction of the theoretical line loss rate of the distribution network after implementing different loss reduction measures. Then, we can target the line loss optimization measures in the line or area, and find the optimal loss reduction measures with great loss reduction potential and high economic benefits. At the same time, we can also provide a theory for the decision-making of distributed photovoltaic planning projects of power companies.

\section{References}

1. T.f. Song. Research on Line Loss Characteristics and Loss Reduction M easures of 10kV Power Grid, Master degree. Thesis, School of Electrical Engineering, Shandong University, 2019.

2. G.U. Jiang, L.U. Lian1, J Y ang. Loss Reduction Potential of Distribution Network Based on Equivalent Resistance and Regression Analysis, Jiangsu Electrical Engineering, 34,61,2005.

3. Y.F. Hu. Research on Line Loss Calculation of $10 \mathrm{kV}$ Distribution Network with DG, M aster degree. Thesis, School of Electrical Engineering, Zhengzhou University, 2017.

4. S.X. Dong. The Research on the Line Loss in the Distrebution Network with Distributed Generations, 
Master degree. Thesis, School of Electrical Engineering, Changsha University of Science and Technology, 2011. 